\title{
Uma Espanhola inglesa abrasileirada
}

\section{Célia Navarro Flores}

\begin{abstract}
Doutora em Língua Espanhola, Literaturas Espanhola e Hispanoamericana pela Universidade de São Paulo. É professora adjunta de Literatura Espanhola e Hispanoamericana da Universidade Federal de Sergipe. Atualmente, desenvolve o projeto de pesquisa, financiado pelo CNPq, "Ariano Suassuna e a Cultura Hispânica". Atua nas seguintes linhas de pesquisa: recepção da obra de Cervantes no Brasil, iconografia do Quixote e Literatura Comparada. É autora do livro Carlos Drummond de Andrade: Cavaleiro de Tristíssima Figura.
\end{abstract}


CARACOL 6 / DOSSIÊ

Palabras clave:

literatura de cordel; Cervantes; adaptação; A espanhola inglesa; o novo cordel.

\section{KEYWORDS}

Cordel Literature; Cervantes; adaptation; The Spanish-English lady; the new cordel.

\section{RESUMO}

Nosso objeto de estudo, neste artigo, é um folheto de cordel publicado no Brasil, em 2008, intitulado

A espanhola inglesa. Trata-se de uma adaptação realizada por Manoel Monteiro do conto homônimo de Cervantes, publicado em 1613, em seu livro Novelas exemplares. O folheto insere-se no que Monteiro chama de "o novo cordel" e foi escrito, a pedido da editora, para fins didáticos. Pretendemos nesse artigo mostrar como, tanto pelo peritexto editorial (Genette, 2009) como pelo texto de Monteiro, o folheto cumpre essa função didática e como esses elementos apontam para seu público-alvo: os jovens estudantes. Por outro lado, pretendemos mostrar que no processo de adaptação (Hutcheon, 2011) o autor nos deixa entrever uma leitura muito particular e brasileira do conto cervantino 
UMA ESPANHOLA INGLESA ABRASILEIRADA

CÉlia Navarro Flores

\author{
Abstract \\ Our object of study, in this paper, is a "cordel" \\ booklet published in Brazil, in 2008, entitled $A$ \\ espanhola inglesa (The Spanish-English lady). The \\ work is an adaptation, by Manoel Monteiro, of the \\ homonymous short story by Cervantes, published in \\ 1613, in his book Novelas ejemplares. The booklet, in \\ keeping with what Monteiro calls the "new cordel", \\ was written, at the publisher's request, for didactic \\ ends. We intend, in this article, to reveal how the \\ booklet fulfills this didactic function, as much in its \\ editorial peritext (Genette, 2009), as in Monteiro's \\ text. As a consequence of these elements, a target \\ public of young students can thus be identified. \\ Furthermore, it will be shown that in the adaptation \\ process (Hutcheon, 2011) the author allows us to see \\ a particular and very Brazilian reading of Cervantes' \\ short story.
}


Alguém já disse que o homem é um animal político; e eu digo que o homem é um animal poético. (Manoel Monteiro)

\section{INTRODUÇÃO}

Quando falamos em recepção da obra de Cervantes no Brasil, geralmente pensamos em seu livro imortal El ingenioso hidalgo Don Quijote de La Mancha, o qual serviu de inspiração a vários escritores brasileiros, tanto na literatura culta quanto na popular. Infelizmente, suas Novelas exemplares não desfrutaram entre nós da mesma popularidade que o Quixote, o que pode ser corroborado tanto pela exígua quantidade de crítica brasileira às Novelas exemplares frente ao Quixote, quanto pelo fato de que nunca tivemos, no Brasil, uma boa edição dessa obra cervantina, como as que temos do Quixote. Talvez a crítica brasileira não tenha se debruçado com tanto empenho sobre as Novelas exemplares porque esta obra inspirou menos artistas brasileiros que a obra magna de Cervantes; entretanto, com as celebrações dos quatrocentos anos das Novelas exemplares, os olhos dos cervantistas do Brasil se voltam para essa obra.

Em busca das repercussões desse livro em nosso país, deparamo-nos com adaptações de dois dos contos das Novelas exemplares para a literatura de cordel brasileira, a saber: A espanhola inglesa, de Manoel Monteiro, e Rodolfo e Leocádia ou a força do sangue, de Arievaldo Viana. Para este trabalho, vamos nos deter no primeiro cordel citado, publicado pela editora Scipione, em 2008. Nossa intenção é mostrar como no processo de adaptação desse conto pelo cordelista podemos entrever uma leitura muito particular do poeta. Sabemos que o processo de adaptação não implica fidelidade ao texto, "os adaptadores são 
UMA ESPANHOLA INGLESA ABRASILEIRADA

CÉlia Navarro Flores

primeiramente intérpretes, depois criadores" (Hutcheon, 20II, 43); por isso é possível investigar como Monteiro, enquanto recriador do conto de Cervantes, imprime sua marca pessoal na história narrada em versos de cordel.

Chamamos a atenção para o fato de que estamos diante de uma adaptação de um gênero literário para outro, igualmente literário, ou seja, da prosa do conto cervantino para a poesia do cordel. Por outro lado, poderíamos supor que estamos diante de dois âmbitos diferentes: o da literatura culta, no qual se inscreve o conto de Cervantes, e a popular literatura de cordel. Porém, como veremos, o folheto em questão se inscreve no que Monteiro chama de "o novo cordel", o qual se distancia do cordel feito por poetas populares. Embora se trate de uma adaptação de um gênero literário para outro, devemos levar em conta que cada gênero tem suas especificidades. No caso da literatura de cordel, temos a restrição do espaço, ou seja, os folhetos em geral são breves, por isso a história deve ser condensada, privilegiando-se as passagens mais importantes para o entendimento global da obra fonte. O cordelista tem de realizar o que Hutcheon denomina "condensações" ou "cortes".

É curioso observar que Manoel Monteiro não foi o primeiro cordelista a adaptar o conto "La española inglesa". Há mais de i6o anos atrás, esta mesma novela foi publicada, em versos, em "pliegos sueltos", em Madri. Caro Baroja nos dá notícias da publicação de três contos de Cervantes, no século XIX: "La española inglesa” (I847), "La gitanilla" (I863) e "La señora Cornelia” (I863). Segundo Baroja:

(...) un ejemplar en cinco pliegos y cuarenta páginas de la "Historia de la gitanilla de Madrid, donde se manifiestan los usos, costumbres y propiedades de los Gitanos. Por D. M. C. S”, impreso en Carmona, en I863, por Don José María Moreno. El mismo, el mismo año publicó en cuatro pliegos y treinta y dos páginas la "Historia de la señorita 
CARACOL 6 / DOSSIÊ

Cornelia y el Duque de Ferrara. Sacada de las obras de D. M. C. y S” (...). En I847, la imprenta madrileña de Marés sacaba en tres pliegos de veinticuatro páginas de papel fuerte la "La Historia del enamorado Ricardo y la hermosa Isabela, llamada la española inglesa. Compuesta en verso y dividida en seis partes. En la que da cuenta de los muchos y raros acontecimientos que sucedieron estos dos amantes". (Caro Baroja, I969, 34I-342)

Infelizmente, não tivemos acesso a essas obras, porém elas são citadas também por Díaz-Maroto $(2000,78)$, quem nos reproduz a primeira página de dois desses cordéis. A título de curiosidade, reproduzimos a página de "La española inglesa” (fig. I):

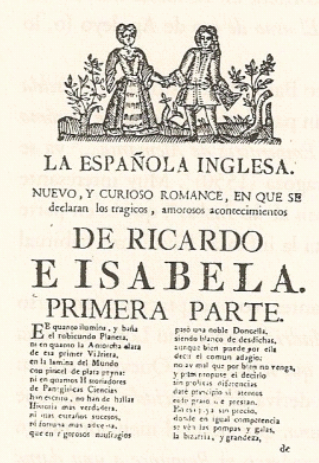

Fig. I

O fato desse conto de Cervantes já ter sido adaptado para o cordel na Espanha, leva-nos a considerar que, de alguma forma, o enredo da história é propício para o gênero literatura de cordel.

Pareceu-nos um passo interessante para este estudo pesquisar, inicialmente, a fortuna desse conto no Brasil, particularmente seu "sucesso": 
UMA ESPANHOLA INGLESA ABRASILEIRADA

CÉlia Navarro Flores

(...) [A] fortuna é o conjunto dos testemunhos que manifestam as virtudes vivas de uma obra. Compõem-se do sucesso de uma parte; e da influência, da outra parte. O sucesso é dado por cifras. É determinado pelo número das edições, das traduções, das adaptações, dos objetos que se inspiram na obra, bem como dos leitores que se supõem terem-na lido. (...) Ao sucesso, quantitativo, opomos a influência qualitativa (...). Se o sucesso se calcula, a influência se aprecia (...). (Brunel, Pichois, Rosseau, I990, 39-40).

Para avaliar o sucesso desse conto em termos quantitativos, procedemos a um levantamento de quatorze edições brasileiras das Novelas exemplares de Cervantes, entre I92I e 20I2, e pudemos observar que o conto "La espanhola inglesa" foi publicado, pela primeira vez no Brasil em uma edição comemorativa dos 350 anos da obra, realizada pela editora Boa Leitura. Desde então, o conto foi publicado mais cinco vezes por diferentes editoras, merecendo uma edição avulsa, em 2005, pela editora Rocco, além da adaptação para o cordel, objeto deste estudo. A partir desse levantamento, podemos dizer que esse conto é relativamente conhecido do público brasileiro, se compararmos com outros contos das Novelas exemplares, como "El coloquio de los perros", publicado no Brasil apenas uma vez, em 2010.

Outro passo importante foi termos entrado em contato com Manoel Monteiro, que nos esclareceu uma série de dúvidas. Pareceu-nos interessante indagar sobre a edição das Novelas exemplares consultada por ele para a recriação em cordel, ou seja, o texto transmissor ou intermediário (Tieghem, apud Nitrini, I997, 32). Monteiro informou-nos tratar-se da edição da Abril Cultural de I97I, a qual adquirimos com a intenção de cotejar o cordel não apenas com a obra de Cervantes, mas com a tradução lida pelo cordelista. Procuramos observar se os momentos em que o cordelista se afasta do texto cervantino são por conta de sua recriação ou por algum motivo relacionado 
ao texto transmissor. Felizmente, constatamos que o texto intermediário não apresentava falhas como cortes ou erros de impressão, o que nos leva a considerar que as diferenças entre o enredo da narrativa do cordel e o do conto de Cervantes, devem-se exclusivamente ao processo criativo de Monteiro e a sua necessidade de condensar a história.

Neste trabalho, buscamos não nos circunscrever à comparação entre o texto de Cervantes e o de Monteiro, mas também analisar o peritexto do cordel em questão, que como veremos está intimamente relacionado aos propósitos da editora e aos preceitos do "novo cordel". Por "peritexto" nos referimos às teorias de Genette, que assim o define:

Denomino peritexto editorial toda a zona do peritexto que se encontra sob responsabilidade direta e principal (mas não exclusiva) do editor, ou talvez, de maneira mais abstrata porém com maior exatidão, da edição, isto é, do fato de um livro ser editado, e eventualmente reeditado, e proposto ao público sob uma ou várias apresentações mais ou menos diferentes. A palavra zona indica que o traço característico desse aspecto do paratexto é essencialmente espacial e temporal; trata-se do peritexto mais exterior: a capa, a página de rosto e seus anexos; e da realização material do livro, cuja execução depende do impressor, mas cuja decisão é tomada pelo editor, em eventual conjunto com o autor: escolha do formato, do papel, da composição tipográfica etc. (Genette, 2009, 2I)

Do peritexto de A espanhola inglesa comentaremos mais detalhadamente as ilustrações, o texto introdutório de autoria de Monteiro e alguns textos incluídos no final do folheto.

Dissemos que o cordel A espanhola inglesa se inscreve no "novo cordel"; vejamos inicialmente como, no Brasil, a literatura de cordel trilha novos caminhos, os quais propiciam sua divulgação e, inclusive, sobrevivência. 
UMA ESPANHOLA INGLESA ABRASILEIRADA

CÉlia Navarro Flores

\section{O NOVO CORDEL BRASILEIRO}

Díaz-Maroto, em seu Panorama de la literatura de cordel española, afirma que, na Espanha, a literatura cordelística desaparece nos anos 70 do século XX; em Portugal, nos anos 80 e "en Brasil continúa relativamente viva en los noventa, así es posible que conozca el siglo XXI" (Díaz-Maroto, 2000, 36). Felizmente, no Brasil, esse gênero literário sobrevive até nossos dias e podemos dizer que, com vigor. Prova disso é a existência de uma Academia Brasileira de Literatura de Cordel, fundada em I988, no Rio de Janeiro, que congrega cordelistas de várias partes do país, e que mantém um vasto acervo de folhetos de cordel.

Entretanto, observamos uma mudança na perspectiva de produção cordelística no Brasil. Embora ainda existam os poetas de corte tradicional, ou seja, aqueles oriundos do campo, que produzem um cordel bastante popular; hoje temos uma nova geração de cordelistas: homens letrados, que além do cordel, exercem outras atividades como o jornalismo, a advocacia, a propaganda etc. Essa nova geração produz o que chamam de "O novo cordel", definido por Manoel Monteiro, o autor de A espanhola inglesa:

Se ontem os poetas eram na sua maioria egressos do campo ou das periferias das urbes, hoje são filhos da cidade, conhecem boa parte do Brasil, e alguns conquistaram uma bagagem cultural invejável. Como resultado, a nova safra de autores de cordel trata de problemas atuais com o mesmo conhecimento e graça que Leandro Gomes de Barros tratou os de sua época. Isso é o que eu chamo o NOVO CORDEL. Esse cordel novo não destoa na poesia, nem nas regras, nem na forma; prima, contudo, pela correção da língua, pela riqueza e pela atualidade das informações. (Monteiro, 2008, 3) 
Os pontos de vendas dessas obras também se diversificaram. No nordeste do Brasil, ainda encontramos os folhetos pendurados em cordéis, vendidos em praças públicas e feiras populares. Entretanto, hoje, eles podem ser adquiridos também nas livrarias locais ou nas virtuais.

Com essa nova geração de cordelistas, o formato dos folhetos também mudou. Hoje, ao lado dos folhetos tradicionais (Io x I5 cm), encontramos cordéis em edições de luxo, profusamente ilustrados, em tamanho grande (I4 x $23 \mathrm{~cm}, 28 \times 20 \mathrm{~cm}, 30 \times 2 \mathrm{Im}$ e outros).

Outra mudança interessante foi com relação à função dos cordéis e seu público-alvo. Se antes os cordéis tinham apenas a função de entretenimento e eram destinados ao público em geral, muitas vezes, pouco letrado, o "novo cordel", além dessas atribuições, passou a ser pensado e utilizado como recurso didático nas escolas brasileiras, destinado a um público infanto-juvenil. Isso levou os novos cordelistas a adaptar grande quantidade de obras literárias brasileiras e estrangeiras para a literatura de cordel, como, por exemplo: Memórias póstumas de Brás Cubas e O alienista, do escritor brasileiro Machado de Assis, A dama das camélias, de Alexandre Dumas Filho, As aventuras de Robson Crusoé, de Defoe, Os miseráveis, de Vitor Hugo, Dom Quixote, de Cervantes entre muitos outros.

O cordel do qual trataremos nesse texto, A espanhola inglesa, foi escrito a pedido da Editora Scipione, para fins didáticos. A editora mantém um Portal Didático, no qual o professor, mediante cadastro, tem acesso aos materiais impressos e vídeos. O cordel, quando comprado pelo professor, vem acompanhado de um guia didático com propostas para sua utilização em sala de aula.

Em nosso modo de ver, essa mudança na produção dos cordéis trazem alguns benefícios: incentiva a leitura dos clássicos (embora não a substitua), 
UMA ESPANHOLA INGLESA ABRASILEIRADA

CÉlia Navarro Flores

divulga e mantém viva a literatura de cordel no país. Esperamos que essa nova postura contribua para que o cordel não desapareça no Brasil.

Vejamos mais detalhadamente o peritexto e o texto do folheto que temos em mãos.

\section{O PERITEXTO}

Podemos afirmar que estamos diante de uma edição, que se não é de luxo é muito bem cuidada, bastante diferente dos cordéis tradicionais. O livro em formato pequeno ( 18 x I2 cm), com 64 páginas e com capa em papel pardo é profusamente ilustrado.

Se antes os cordéis eram ilustrados apenas com uma gravura impressa na capa, de autoria de artistas populares, hoje o "novo cordel" traz excelentes ilustrações de artistas premiados. É o caso de A espanhola inglesa, que traz, além da capa, I8 páginas ilustradas por Jô Oliveira (capa e páginas: 4, 7, IO, I3, I6, 20, 24, 26, 27, 30, 33, 35, 38, 39, 42, 46, 51 е 53). Várias dessas ilustrações retratam duas cenas simultaneamente, uma na parte superior e outra na parte inferior (páginas: 4, 7, 27, 30, 35 e 38). Essa abundância de ilustrações, por um lado, torna o livrinho bastante atrativo, principalmente se pensarmos que seu público-alvo são os jovens. Por outro lado, as ilustrações em si já contam a história. Como afirmou Monteiro sobre o ilustrador, em mensagem eletrônica enviada: "Ele [Jô Oliveira] faz um registro tão original da história que a mesma pode ser lida até sem palavras, como ocorreu n'O gato de botas, da FTD, onde a metade do livro mostra toda história só no olhar as ilustrações.".

A capa (fig. 2) traz a ilustração do momento do casamento de Recaredo e Isabel. O rapaz coloca a aliança no dedo de sua amada diante da rainha. Como veremos, Monteiro altera o final da história. Isabel e Recaredo são representados 
CARACOL 6 / DOSSIÊ

como sendo bastante jovens, novamente, a intenção é atrair ao público juvenil. Na parte superior temos o título da obra, o nome do autor, a informação de que o livrinho foi "baseado na obra de Miguel de Cervantes" e abaixo, temos o nome do ilustrador.

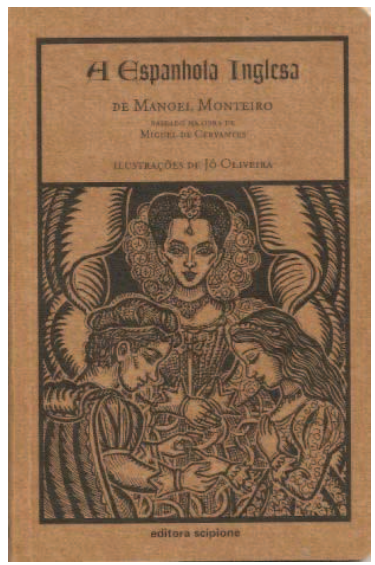

Fig. 2

Chamou-nos a atenção a dramaticidade de algumas ilustrações como a da página 39. Na parte superior, temos o desenho da camareira com o copo de veneno. No texto do cordel, a camareira é chamada de "bruxa" e a figura da ilustração, de fato, remete-nos às bruxas dos contos de fadas, com seu nariz longo e dentes à mostra; por sua vez o veneno fumegante no copo, remete-nos às poções mágicas das histórias infantis. Na parte inferior, temos Isabel em um gesto dramático, com os olhos arregalados e a mão na garganta (fig. 3). 
UMA ESPANHOLA INGLESA ABRASILEIRADA

CÉlia Navarro Flores

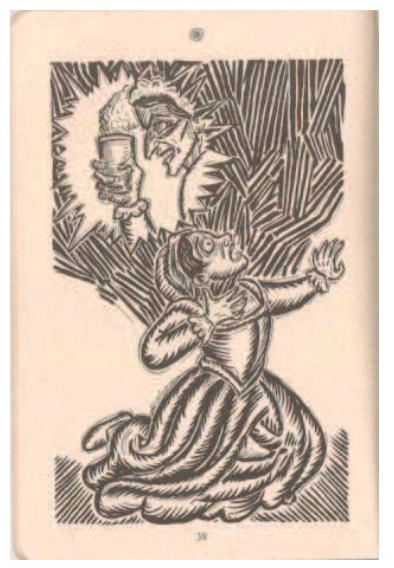

Fig. 3

Outra ilustração chamativa é a de Isabel após ter tomado o veneno (fig.4). Como veremos, Monteiro foi bastante condescendente ao descrevê-la: "Pior é que a cada dia / ficava desfigurada, / o cabelo bem pouquinho / a pele toda enrugada" (Monteiro, 2008, 37), uma vez que Cervantes a descreve como um monstro: "la naturaleza lo comutó en dejarla sin cejas, pestañas y sin cabello, el rostro hinchado, la tez perdida, los cueros levantados y los ojos lagrimosos. Finalmente, quedó tan fea que (...) parecía un monstruo de fealdad" (Cervantes, 2000, 247). O ilustrador, por sua vez, parece ter sido mais fiel à representação de uma Isabel cervantina, pois a retrata bastante feia. 
CARACOL 6 / DOSSIÊ

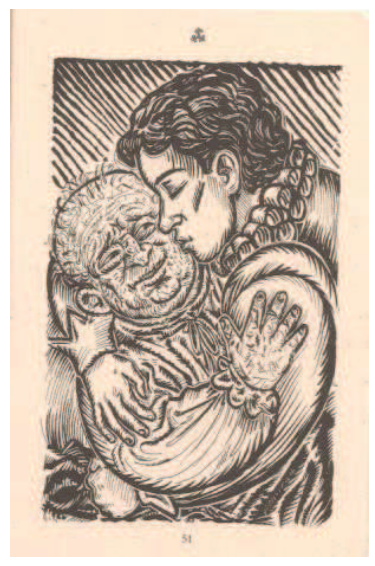

Fig. 4

O livro traz uma introdução escrita por Monteiro, intitulada "O novo cordel vai à escola", na qual o autor fala sobre as origens do cordel, sobre sua disseminação no Brasil, sobre os temas e os principais cordelistas brasileiros e, finalmente, define o que ele chama de "novo cordel", texto reproduzido acima.

Ao final do livro, temos dois textos: um deles intitulado "A espanhola inglesa. Adaptação de um clássico para a literatura de cordel”, de Cláudio Henrique Salles Andrade, doutor pela Universidade de São Paulo; e, outro, uma breve biografia de Cervantes, por Amanda Valentim, mestranda em Língua Espanhola pela USP, intitulada “Miguel de Cervantes”.

Andrade, em seu texto, informa-nos que o conto pertence às Novelas exemplares de Cervantes. Na sequência, discorre sobre o enredo do cordel A espanhola inglesa. Posteriormente, o autor trata da metrificação dos cordéis no Brasil e de seus principais temas, os quais ele divide em três grupos: cantorias e pelejas, poemas de época ou acontecidos, e romances e histórias. Segundo o autor, o cordel A espanhola inglesa, pertence a este terceiro tipo. Finalmente, 
UMA ESPANHOLA INGLESA ABRASILEIRADA

CÉlia Navarro Flores

Andrade comenta o cordel em tela. Valentim, por sua vez, limita-se à biografia de Cervantes. Após o texto de Valentim, temos as fotos de Manoel Monteiro e Jô Oliveira, com suas respectivas biografias resumidas.

Na quarta capa, temos mais um pequeno texto de Andrade, no qual são reproduzidos alguns parágrafos de seu texto anterior. No parágrafo introdutório, Andrade diz "Nessa narrativa você seguirá a trajetória de dois jovens apaixonados por caminhos tortuosos, cheios de obstáculos, desencontros e surpresas. A obra ilustra o valor de virtudes como a paciência na adversidade, a constância no amor, a coragem, a astúcia e a inteligência” (Andrade, 2008, quarta capa).

$O$ peritexto se mostra bastante coerente com a finalidade para a qual a editora Scipione publicou a obra. A abundância de ilustrações -algumas nos remetem ao universo dos contos de fadas-e a brevidade dos textos indicam que o público-alvo é o infanto-juvenil. Por outro lado, a preocupação em contratar um bom cordelista como Monteiro e um reconhecido ilustrador, apontam para o cuidado que a editora teve por se tratar de uma obra destinada a ser utilizada como recurso didático.

\section{O POEMA}

Monteiro, na mensagem eletrônica recebida, fala sobre seu processo criativo ao adaptar a obra de Cervantes: “(...) li e reli diversas vezes A Espanhola para tomar posse do corpo e da alma do texto, este é meu processo, quando me senti íntimo da espanholinha, do seu captor, do tempo e do espaço em que ocorre o evento, comecei engendrar os primeiros versos". Vejamos mais detidamente, como se concretiza essa experiência do poeta; para isso, vamos recontar resumidamente a história contida no cordel brasileiro, apontando 
CARACOL 6 / DOSSIÊ

os momentos em que esta se distancia da obra cervantina e tecendo alguns comentários sobre estes distanciamentos.

O poeta inicia o cordel com um recurso da poesia épica: a invocação à musa:

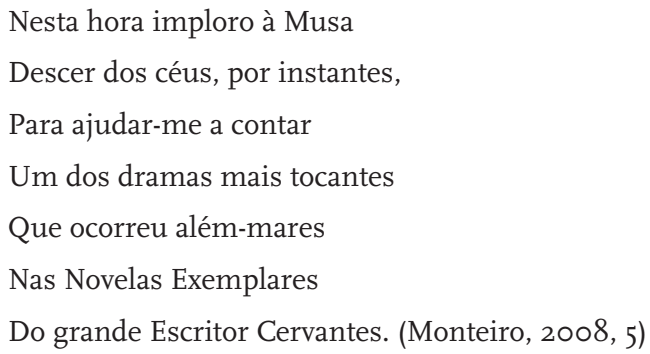

A história contada, A espanhola inglesa, é considerada, pelo poeta, a mais bonita das escritas por Cervantes:

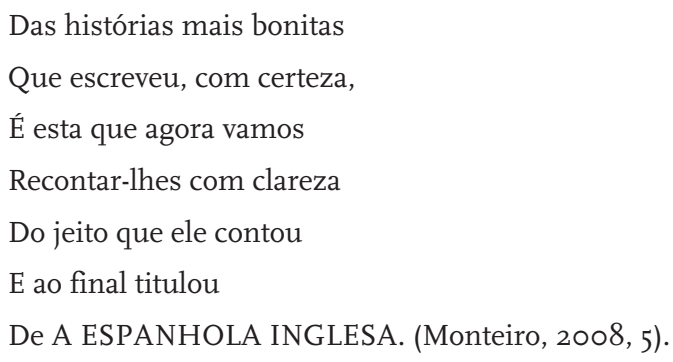

O poeta conta o rapto de Isabel, aos sete anos, pelos "ingleses brutais" (Monteiro, 2008, 5). Na sequência, menciona que a rainha da Inglaterra mandava seu "pessoal (...) roubar para o cofre real" (Monteiro, 2008, 5), expressando uma imagem bastante negativa dos ingleses, diferentemente de Cervantes que é condescendente com o inimigo. Curiosamente, em uma 
UMA ESPANHOLA INGLESA ABRASILEIRADA

CÉlia Navarro Flores

digressão, o "eu lírico" compara o poderio inglês da época com as grandes potências atuais:

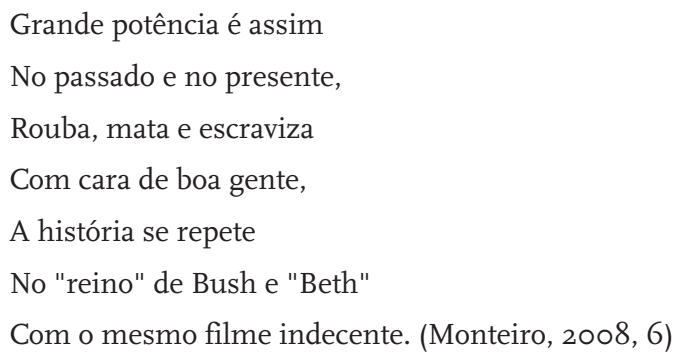

Nesse momento, o autor posiciona-se criticamente contra o poderio das grandes potências, as quais, segundo ele, ainda hoje roubam, matam e escravizam. Essa indignação é observada também em seu correio eletrônico, quando nos diz:

Falei (...) do Presidente dos Estados Unidos de então, da Rainha Elizabete e disse que: Os corsários de ontem e de hoje estiveram e estão sempre a serviço da Coroa. O competente professor da USP que fez a crítica para o livro/cordel aprovou a minha ousadia. Mesmo que ele não tivesse aprovado eu não mudaria uma vírgula porque a verdade é para ser dita. (Mensagem eletrônica)

Após essa interessante digressão, volta-se à história da espanhola inglesa, destacando-se que a armada inglesa assaltou Cádiz, sequestrou uma menina, a qual o Capitão Clotaldo deu de presente à mulher. A menina "deu-se bem com Recaredo", filho do casal. Na sequência, em uma estrofe que começa e termina por parêntesis, fala-se sobre a questão religiosa, explica-se que a família de Clotaldo era católica, embora soubesse que a rainha era anglicana. 
CARACOL 6 / DOSSIÊ

A presença dos parênteses indica que se trata de uma poesia para ser lida, não propriamente cantada ou recitada, uma vez que oferece explicações entre parênteses mais adequadas ao texto escrito.

Entre Recaredo e Isabel nasce um "inefável carinho" (Monteiro, 2008, 8). Enquanto na obra de Cervantes, Catalina "como si fuera su hija, la [Isabel] criaba, regalaba, e industriaba" (Cervantes, 2000, 219), Monteiro descreve Isabel mais como uma criada que como uma filha: “(...) Servindo enquanto ganhava / pequenos nacos de amor" (Monteiro, 2008, 9). Surge o amor entre os dois jovens: "Recaredo e Isabel/ entreolharam-se a rir, e um amorzinho cego,/ principiou a surgir" (Monteiro, 2008, 9). Os olhares, o riso e a palavra "amorzinho" em diminutivo nos sugerem um amor pueril; tal imagem é reforçada pela gravura na qual Isabel e Recaredo estão sentados em um banco embaixo de uma árvore: ela com agulha e bordado na mão, o corpo virado em sentido contrário à figura de Recaredo, demonstrando seu recato; o braço de Recaredo sobre o encosto do banco envolvendo as costas de Isabel; ambos entreolhando-se e sorrindo.

Na sequência, Monteiro faz uma bela descrição de Isabel:

Isabel era o retrato

Dum anjo recém-pintado,

Tinha a boca de papoula,

A voz de pífaro afinado

Soava como um cicio,

A tez de cetim macio,

O corpo bem torneado.

O rosto moreno-claro,

Com um leve riso no cenho, 
UMA ESPANHOLA INGLESA ABRASILEIRADA

CÉlia NAVARro Flores

Do jeito que Monalisa

Tem no suave desenho,

As sobrancelhas artísticas

Com as características

Dum espécime madrilenho.

Os cabelos fios negros,

Deslizavam em catarata

Pelos seus ombros bem feitos,

Como a água de cascata.

Despenca rochedo abaixo

Para cair no riacho

Que abre sendas na mata. (Monteiro, 2008, II)

Tal descrição nos remete à arte da pintura: "retrato", "recém-pintado", "desenho", "artísticas” e a comparação com o sorriso de Monalisa. A Isabel, de Monteiro, é morena, com os cabelos negros, enquanto a de Cervantes é loura: “sus mismos cabellos, que eran muchos, rubios y largos" (Cervantes, 2000, 224). É possível que haja aqui um acionamento do estereótipo da mulher espanhola, à qual associamos a figura de Carmen: a morena aciganada e sensual. Embora, no princípio do poema, Monteiro haja feito alusão a Cádiz, nessa descrição diz que Isabel tem características das mulheres madrilenas.

Na sequência, páginas I2 a I5, o poeta destaca o casamento arranjado entre Recaredo e a jovem nobre e relata como o rapaz adoece de amor e, consequentemente, como seus pais consentem em seu matrimônio com Isabel, fato que por sua vez produz admiração na corte. Por intermédio de um recurso típico da literatura de cordel - o diálogo introduzido por travessão - a rainha dirigindo-se a Clotaldo, declara: 
CARACOL 6 / DOSSIÊ

- Alto lá, só um momento,

Seu filho para casar

Antes vai ter de provar

Que tem merecimento.

Você manteve a garota

Presa na sua cozinha

Sabendo que por direito

A sua posse era minha,

Por causa disso, lhe digo,

Ela vai ficar comigo,

seu filho vai pra marinha.

Pra comandar um navio,

Neste instante dou-lhe o posto,

Zarpará amanhã mesmo.

Se for sagaz e disposto,

Trouxer muito ouro de lei,

Quando voltar eu farei,

Seu casamento com gosto. (Monteiro, 2008, I5)

Isabel consente em ficar no palácio e em esperar a volta de Recaredo. Nesse momento, o texto toca em um dos temas principais da novela cervantina: a inveja, traduzida no cordel pelos ciúmes.

Ficarei para servir

Vossa graça, hoje meu sol.

Disse isso solfejante

Num delicado espanhol,

Sua voz, rosto e perfume 
UMA ESPANHOLA INGLESA ABRASILEIRADA

CÉlia Navarro Flores

Já despertavam ciúme

$\mathrm{Na}$ vassalagem reinol.

O ciúme é um defeito

Que a humanidade tem.

Se alguém é rico e bonito,

Todos querem ser também.

Se um afundar ou cair

Para ajudá-lo a emergir

Difícil surgir alguém. (Monteiro, 2008, I7)

O episódio da batalha contra os turcos, a vitória e a generosidade de Recaredo são condensados em sete estrofes. Recaredo conhece os pais de Isabel e os leva perante a rainha. A mãe de Isabel a reconhece pelo sinal que a menina leva atrás da orelha, e, em seguida, desmaia. Comicamente, para a mãe de Isabel recobrar a consciência dão-lhe "chá mate bem quente/ adocicado com mel" (Monteiro, 2008, 3I). O chá mate, típico da América, não possui as qualidades terapêuticas atribuídas a ele no poema, porém sua menção aproxima do leitor brasileiro o conto de Cervantes.

Protela-se o casamento a pedido da camareira da rainha, cujo filho, o Conde Arnesto, estava enamorado de Isabel. Esse personagem é descrito na obra de Cervantes como "arrogante, altivo y confiado" (Cervantes, 2000, 242) e de "arrojada condición", (Monteiro, 2008, 243). Monteiro, por sua vez o descreve como um libertino "namorador", que quer se deitar com Isabel, prometendolhe casamento. Personagem este que, tanto na obra de Cervantes quanto na de Monteiro, remete-nos à figura de Don Juan. O fragmento começa com uma pergunta dirigida ao leitor/ouvinte, outra marca da oralidade do cordel: 
CARACOL 6 / DOSSIÊ

Lembra a camareira a quem

Isabel foi confiada?

Pois bem, ela tinha um filho

De conduta desregrada,

Militar, namorador,

Que logo caiu de amor

Pela recém-agregada.

A beleza de Isabel

Chamou sua atenção

Com seu jeito sensual,

Seu corpo violão.

Arnesto pensou consigo,

Essa aí não tem perigo,

Vai cair no meu colchão.

E começou dando em cima

Da inocente donzela,

Oferecendo presentes,

Soltando gracinha a ela,

Falando até em casar,

Sem ao menos respeitar

O noivado de Isabela. (Monteiro, 2008, 32)

A sensualidade de Isabel, anunciada em sua descrição, é reiterada nos versos: "Com seu jeito sensual/ Seu corpo violão". Na sequência, Arnesto ameaça matar Recaredo:

E disse à mãe: - Eu lhe juro,

Se Isabela me enjeitar,

Eu não respondo por mim, 
UMA ESPANHOLA INGLESA ABRASILEIRADA

CÉlia NAVARro Flores

Viver não quero e matar

Com certeza matarei,

Porque não permitirei

Recaredo me ganhar. (Monteiro, 2008, 34)

Ao declarar tal pretensão, o personagem de Monteiro se alinha com os bandidos, malvados e valentões que povoam a literatura de cordel tanto brasileira quanto espanhola.

A camareira pede o adiamento das bodas, a rainha nega e Arnesto desafia Recaredo para um duelo. Recaredo manda avisar a rainha, a qual ordena que Arnesto seja preso. A camareira dá o veneno à Isabel e o médico, um antídoto. O poeta dramatiza o momento: "Então do dia pra noite / Isabel mudou de sorte; / Em vez do seu Recaredo, / Seu noivo agora era a morte.” (Monteiro, $2008,37)$. O poeta descreve a feiura de Isabel, de maneira bem menos cruel que Cervantes, como comentamos anteriormente.

Monteiro conta sobre os cuidados dos médicos, o aprisionamento de Arnesto e sua mãe. Clotaldo e Catalina trazem a "moça rica”, a nobre com a qual Recaredo se casaria. Recaredo rechaça a moça, a qual, por sua vez, também está apaixonada por outro. Aqui, o poeta traz elementos da sabedoria popular, representada pelos "velhos":

Tal como os velhos já dizem,

Amor não se escolhe a dedo,

Não chega tarde demais

Nem chega muito cedo.

Chega quando quer chegar,

Como chegou pra ficar

No peito de Recaredo. (Monteiro, 2008, 45) 
CARACOL 6 / DOSSIÊ

A nobre se despede de Clotaldo e Catalina, deixando Recaredo "Amargando a crua sina. / De ver a noiva prostrada, / Padecendo envenenada / Por uma 'bruxa' assassina." (Monteiro, 2008, 44). Recaredo decide casar-se com Isabel e novamente o narrador discorre sobre o amor, tema fundamental no texto de Cervantes:

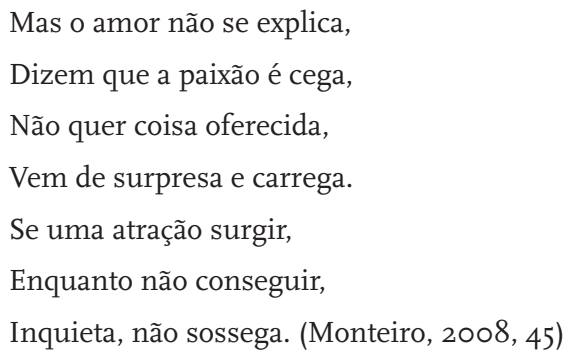

Podemos notar o didatismo em Monteiro, quando, na página I7, fala sobre o ciúme, e nesses dois últimos fragmentos em que fala do amor. Há uma intenção de ensinar as virtudes aos jovens. Lembremos o caráter exemplar das Novelas exemplares de Cervantes e a intenção do uso do cordel em sala de aula, para um público jovem.

$\mathrm{Na}$ sequência, Recaredo pede Isabel em casamento e conta com o consentimento da rainha, que por sua vez promove a festa. Nesse momento, o poeta chama a atenção do leitor sobre as diferenças religiosas:

O leitor deve lembrar,

Pois lá atrás já falamos:

Os Clotaldo eram católicos

Como Isabel, e notamos

Que ela guardou segredo

Dessa fé de Recaredo

Até a hora que estamos. (Monteiro, 2008, 49) 
UMA ESPANHOLA INGLESA ABRASILEIRADA

CÉlia Navarro Flores

Monteiro, no processo de condensação, descarta toda sequência da obra de Cervantes que supõe o casamento de Recaredo (em segredo), a ida de Isabel para Sevilha a mando da rainha, a ida de Recaredo para Roma e, posteriormente, sua captura pelos turcos e resgate pelos padres. Nada se diz sobre a carta de Catalina relatando sobre a morte de seu filho, tampouco sobre a recuperação de Isabel e sua decisão de entrar para o convento.

Diferentemente da obra de Cervantes, no cordel, Isabel e Recaredo se casam na Inglaterra. Isabel, devota de Santiago de Compostela, pede a Recaredo para prometer-lhe que percorreriam o caminho de Santiago. O santo ouve o pedido de Isabel e intercede por ela. Após a festa de casamento e sua consumação permeada por um erotismo sutil, ocorre um milagre:

Recaredo e Isabela,

Agora, sim, dois amantes,

Entregaram-se um ao outro

Já nos primeiros instantes,

Numa volúpia incontida,

Confiantes que na vida

Tem o depois e o antes.

Foi uma noite de amor

Pra amante não pôr defeito,

Entre um gemido e um beijo

Fez-se o que era pra ser feito.

Quando a aurora surgiu,

Recaredo olhou e viu

Um anjo ao lado em seu leito. 
CARACOL 6 / DOSSIÊ

Isabel estava linda,

Com um sorriso atraente,

$\mathrm{O}$ rosto suave e belo,

A pele sedosa e quente.

A boca pedindo um beijo

Anunciava o desejo

De amar repetidamente. (Monteiro, 2008, 52)

$\mathrm{Na}$ última estrofe, o poeta diz que espera que Cervantes não se incomode por ele ter modificado o final, o qual deixava o cordelista satisfeito. Talvez o aviso da alteração do final da história se deva ao fato de que o cordel foi pensado como recurso didático. Seria uma maneira de dizer que a história contada não é fiel ao original, instigando a curiosidade do estudante em conhecer o desfecho dado por Cervantes.

Foram felizes pra sempre

São Tiago quis assim,

Mas só não sei dizer se

Saavedra achou ruim

Ter findado desse jeito.

Eu mesmo estou satisfeito

Com este desfecho. FIM. (Monteiro, 2008, 52)

Embora, no início, o narrador tenha dito que recontaria a história "Do jeito que ele [Cervantes] contou" (Monteiro, 2008, 5), no final faz alterações que por sua vez enveredam pelos caminhos do fantástico: São Tiago opera um milagre que faz com que Isabel volte a ser bela, da noite para o dia. Tal modificação nos indica uma tentativa de aproximar a narrativa de Cervantes do público brasileiro, o qual aprecia histórias com final feliz e com elementos fantásticos. 
UMA ESPANHOLA INGLESA ABRASILEIRADA

CÉlia Navarro Flores

Finalmente, chamamos a atenção para a preocupação com a língua portuguesa. Os versos muito bem escritos trazem expressões muitas vezes pouco usuais na língua oral como: "Osculou-lhe a face pálida", na página 4 ou "ordenou os esponsais", página 45 entre outras.

\section{COMENTÁRIOS FINAIS}

Como pudemos observar ao longo deste trabalho, o cordel brasileiro continua vivo graças às transformações ocorridas em sua produção, uma delas é a intenção de levar os clássicos da literatura universal às salas de aula, em uma linguagem moderna e bem cuidada, como é o caso da obra que comentamos A espanhola inglesa. Tanto a forma quanto o conteúdo da obra mostra uma preocupação por parte da editora em levar um livro de qualidade para a sala de aula.

O seu peritexto corresponde às intenções da editora. As inúmeras e ótimas ilustrações, os textos breves e de autores vinculados à academia nos mostram que o público-alvo é o juvenil e sua função é a didática.

Por outro lado, o texto de Monteiro nos deixa entrever suas intervenções, as quais nos mostram uma leitura particular: a descrição de Isabel como uma morena sensual, arquétipo de Carmen; a crítica à política da época ao mencionar Bush e "Beth"; a referência a uma bebida típica da América do Sul, e a alteração do final do conto - a qual, por um lado deve-se à condensação necessária à adaptação e por outro a uma intenção de adequar à obra ao público brasileiro. $\mathrm{O}$ didatismo, observado nos textos breves que compõem o peritexto, é reforçado no texto de Monteiro tanto pela preocupação com a língua portuguesa quanto pelos momentos em que se critica a inveja ou quando o poeta traz a experiência dos "velhos". 
CARACOL 6 / DOSSIÊ

A espanhola inglesa é um conto que contém alguns dos ingredientes que provavelmente atraem as gerações mais jovens, como os temas do amor, aventuras, vingança e inveja. Contada em versos por Manoel Monteiro em um livro fartamente ilustrado por Jô Oliveira, temos uma obra que reconta a história de Cervantes, entremeando-a com uma visão particular da novela cervantina em conjunção com a cultura espanhola.

\section{REFERÊNCIAS BIBLIOGRÁFICAS}

Brunel, P; Pichois, Cl.; Rosseau, A. M. Que éliteratura comparada? São Paulo: Perspectiva, Editora da Universidade de São Paulo; Curitiba: Editora da Universidade Federal do Paraná, I990.

Caro Baroja, Julio. Ensayo sobre la Literatura de Cordel. Madrid: Revista de Occidente, 1969.

Cervantes, Miguel de. Novelas ejemplares. Edición de Jorge García López. Barcelona: Crítica, 200I.

Genette, Gérard. Paratextos editoriais. Tadução Álvaro Faleiros. Cotia (SP): Atelier editorial, 2009 .

Hutcheon, Linda. Uma teoria da adaptação. Florianópolis: Ed. da UFSC, 20 II. Mendoza Díaz-Maroto, Francisco. Panorama de la Literatura de Cordel Española. Madrid: Ollero \& Ramos, 2000.

Monteiro, Manoel. A espanhola inglesa. São Paulo: Scipione, 2008.

Nitrini, Sandra. Literatura comparada. São Paulo: Edusp, I997.

Viana Lima, Arievaldo. Rodolfo e Leocádia. A força do sangue. Fortaleza: Tupynanquim Editora, 200I. 


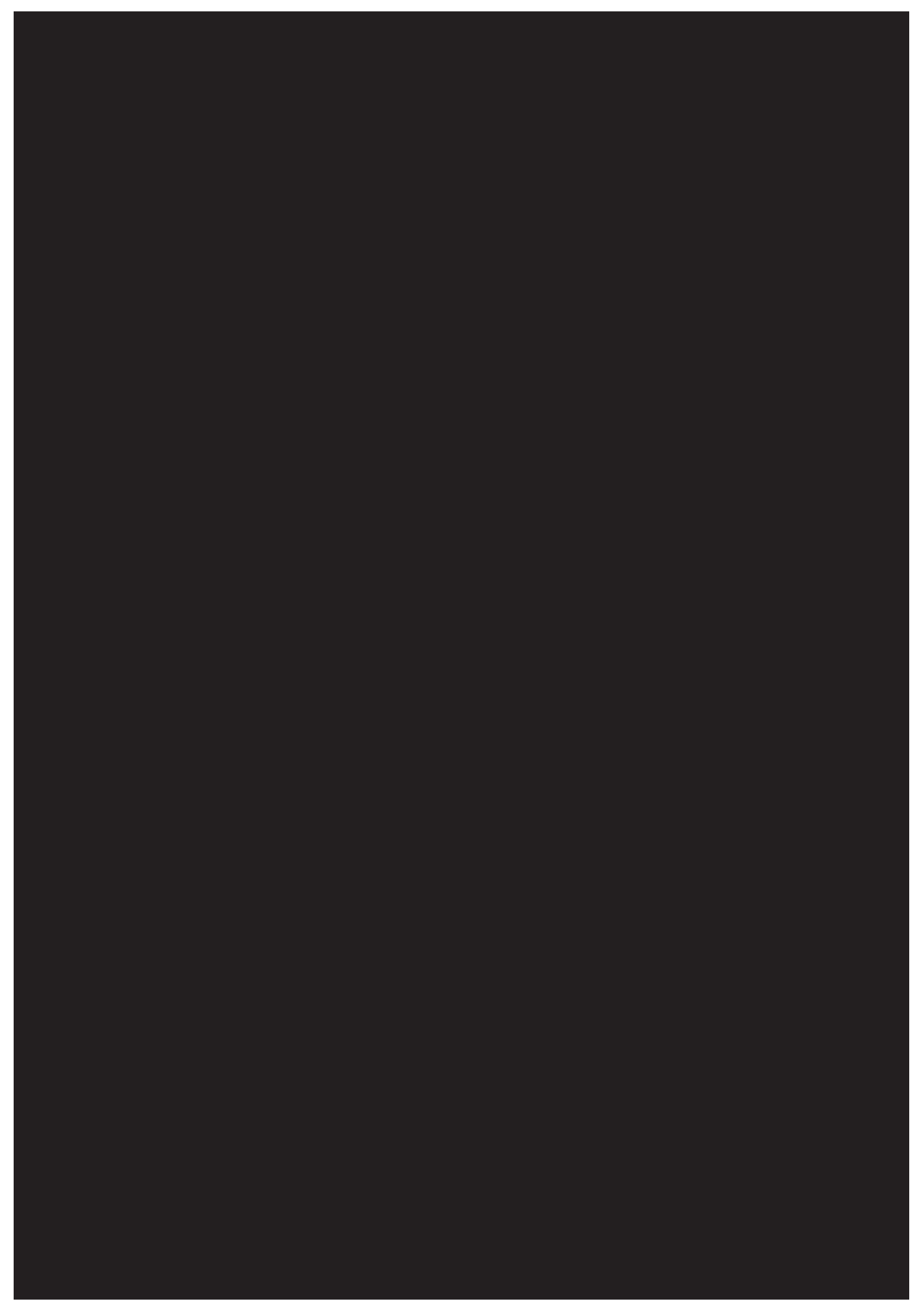

